\title{
Dynamic and differential changes in myocardial and plasma endothelin in patients undergoing cardiopulmonary bypass
}

M. Marlina Multani, MS

John S. Ikonomidis, MD, PhD

Peter Y. Kim, MD

Elizabeth A. Miller, MD

Kim J. Payne, MD

Rupak Mukherjee, $\mathrm{PhD}$

B. Hugh Dorman, MD, PhD

Francis G. Spinale, MD, PhD
From the Medical University of South Carolina, Charleston, SC.

Received for publication Dec 11, 2003; revisions received June 21, 2004; accepted for publication July 6, 2004.

Address for reprints: Francis Spinale, MD, $\mathrm{PhD}$, Cardiothoracic Surgery, Room 625, Strom Thurmond Research Building, 770 MUSC Complex, Medical University of South Carolina, 114 Doughty St, Charleston, SC 29425 (E-mail: wilburnm@ musc.edu).

J Thorac Cardiovasc Surg 2005;129:584-90 $0022-5223 / \$ 30.00$

Copyright $\odot 2005$ by The American Association for Thoracic Surgery

doi:10.1016/j.jtcvs.2004.07.018
Objective: The bioactive peptide endothelin modulates left ventricular function by changing afterload, coronary vascular tone, and myocardial contractility. However, whether increased plasma endothelin levels observed in patients during and after coronary revascularization and cardiopulmonary bypass reflect actual myocardial interstitial levels are unknown.

Methods: A microdialysis probe (outer diameter: $0.77 \mathrm{~mm}$; length: $4 \mathrm{~mm}$ ) was placed in the left ventricular apical midmyocardium in 20 patients and myocardial interstitial fluid was collected $(2.5 \mu \mathrm{L} / \mathrm{min})$ at baseline and up to 30 minutes after cardiopulmonary bypass. Myocardial interstitial and systemic arterial endothelin were measured by radioimmunoassay.

Results: Baseline myocardial interstitial endothelin was over 6-fold higher than plasma $(20.11 \pm 2.07$ vs $3.19 \pm 0.25 \mathrm{fmol} / \mathrm{mL}, P<.05)$. Plasma endothelin increased by $23 \% \pm 12 \%$ at 60 minutes of cardiopulmonary bypass whereas myocardial interstitial endothelin increased by $105 \% \pm 24 \%, P<.05$ ), and this change was higher than in the plasma $(P<.05)$. Although no further change in plasma endothelin occurred during cardiopulmonary bypass, myocardial interstitial levels increased further after crossclamp removal $(400 \% \pm 75 \%)$ and remained significantly higher than plasma at separation from cardiopulmonary bypass.

Conclusion: The unique findings of this study were 2-fold: First, significant compartmentalization of endothelin exists within the human myocardium. Second, a significantly higher and temporally disparate change in myocardial interstitial endothelin occurs during and after cardiopulmonary bypass when compared with systemic levels. These dynamic changes in myocardial endothelin likely influence coronary vascular tone and contractility.

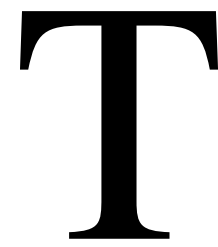

he bioactive peptide endothelin-1 (ET) modulates left ventricular (LV) function by changing afterload and coronary vascular tone and through direct effects on myocardial contractility. ${ }^{1-3}$ Increased ET production has been demonstrated in a number of cardiovascular disease states including pulmonary hypertension, myocardial infarction, and congestive heart failure. ${ }^{1-5}$ Increased plasma ET has also been documented in patients undergoing cardiac surgery. ${ }^{6-10}$ Moreover, past studies have demonstrated that in patients undergoing coronary revascularization and car- 

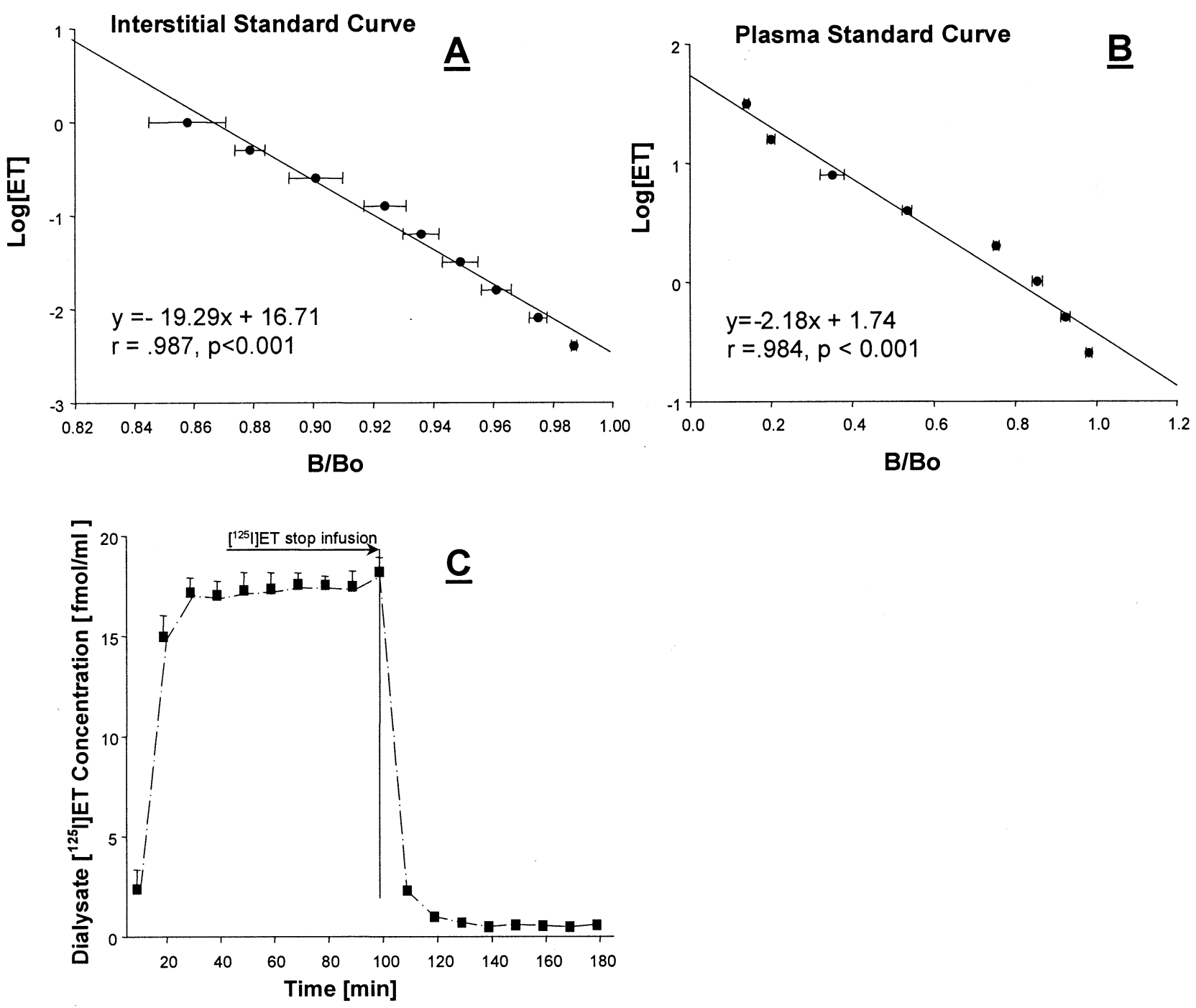

Figure 1. A linear regression analysis was used for both interstitial $(A, 0.003$ to $1 \mathrm{fmol} / \mathrm{mL}$ ) and plasma (B, 1 to 32 $\mathrm{fmol} / \mathrm{mL})$ ET measurements. The $x$-axis denotes the quotient of bound and total ligand $E T\left(B / B_{0}\right)$, and the $y$-axis denotes the logarithmic transformation for known ET concentrations. The standard curves were repeated in 10 independent runs during the execution of the study. C, In vivo measurements of interstitial ET demonstrated steady-state levels for 6 hours after probe placement. Infusion of radiolabeled ET demonstrated compartmentalization of the bioactive peptide around the probe, which was immediately recovered at termination of the infusion.

diopulmonary bypass (CPB), systemic ET levels increase during the operative procedure and can remain elevated postoperatively. ${ }^{6-9}$

ET is produced by a number of cell types including endothelial cells, smooth muscle cells, and cardiac myocytes. ${ }^{1-4}$ A past study demonstrated that in patients undergoing cardiac surgery, myocardial production of ET increased after $\mathrm{CPB} .{ }^{7}$ These findings suggest that ET may be produced and released into the myocardial interstitium. However, local myocardial interstitial ET levels have never been directly measured in humans. Accordingly, the overall goal of this study was 2-fold: first, to determine the relationship between systemic and myocardial levels of ET in patients undergoing cardiac surgery; second, to examine myocardial levels of ET within the myocardium of patients during and immediately after CPB.

\section{Methods}

Patients

The protocol was approved by the Human Subjects Review Committee of the Medical University of South Carolina and the Veterans Affairs Medical Center. Twenty patients undergoing elective 
TABLE 1. Patient characteristics and perioperative data

\begin{tabular}{lc}
\hline Sample size (n) & 20 \\
Age (y) & $62 \pm 9$ \\
Sex & \\
$\quad$ Male & 15 \\
$\quad$ Female & 5 \\
Ejection fraction (\%) & $53 \pm 11$ \\
Medication profile (\% of sample size) & \\
$\quad$ Beta blockade & 55 \\
Ca $^{2+}$ channel blockers & 35 \\
ACE inhibitors & 15 \\
$\quad$ Diuretics & 15 \\
$\quad$ HMG-CoA reductase inhibitors (statins) & 20 \\
No. grafts & $3 \pm 1$ \\
Crossclamp duration (min) & $68 \pm 15$ \\
Cardiopulmonary bypass duration (min) & $87 \pm 17$ \\
Surgery duration (min) & $258 \pm 44$ \\
Duration of stay in intensive care unit (d) & $2.4 \pm 1.1$ \\
Postoperative hospital stay (d) & $9 \pm 5$ \\
\hline
\end{tabular}

Values presented as mean \pm standard deviation

coronary artery bypass surgery requiring CPB provided informed consent to participate in this study. Demographic and perioperative data for these patients are provided in Table 1. Initial cardioplegia was accomplished with antegrade administration of 200 to $250 \mathrm{~mL}$ of normothermic cardioplegic solution containing 4 parts blood to 1 part $\mathrm{D}_{5} \mathrm{~W} 0.2 \mathrm{NaCl}$ containing $29 \mathrm{~mL}$ of tromethamine buffer, 34 $\mathrm{mL}$ of adenosine citrate phosphate dextrose, and $30 \mathrm{mEq} / \mathrm{L}$ of KCL. This was followed immediately by retrograde administration of $1000 \mathrm{~mL}$ of hypothermic $\left(5^{\circ} \mathrm{C}\right) 4: 1$ blood:crystalloid cardioplegic solution. At 20-minute intervals cardioplegia was maintained with retrograde administration of 200 to $500 \mathrm{~mL}$ of the cardioplegic solution with a lower $\mathrm{KCl}$ concentration $(15 \mathrm{mEq} / \mathrm{L})$. Before removal of the crossclamp, a 500- to $750-\mathrm{mL}$ dose of terminal normothermic cardioplegic solution was given. At the termination of $\mathrm{CPB}$, heparin was neutralized with protamine in a 1:1 ratio.

\section{Myocardial Microdialysis and Plasma Collection}

Myocardial microdialysis studies have been performed previously and the technique was adapted for this study. ${ }^{11-13}$ A probe containing a $4 \mathrm{~mm}$-long membrane was used $(20 \mathrm{kDa}$; outer diameter of probe shaft, $0.77 \mathrm{~mm}$; outer diameter of probe membrane, 0.5 mm; CMA/Microdialysis, North Chelmsford, Mass). The probe was placed into the LV apical midmyocardium and prepared for dialysate collection. A radial artery was catheterized and used to obtain systemic samples. Systemic and myocardial interstitial samples were collected at baseline and up to 30 minutes post-CPB.

\section{ET Analytical Measurements}

Plasma and dialysate samples were first eluted over a cation exchange column (C-18 Sep-Pak; Waters Associates, Milford, Mass) and then dried by vacuum centrifugation. The samples were reconstituted in $0.02 \mathrm{~mol} / \mathrm{L}$ borate buffer, and a high-sensitivity radioimmunoassay was performed (RPA 545, Amersham, Arlington Heights, Ill). After incubation of samples with ${ }^{125}$ I-labeled ET and ET specific antibody, a charged secondary antibody was

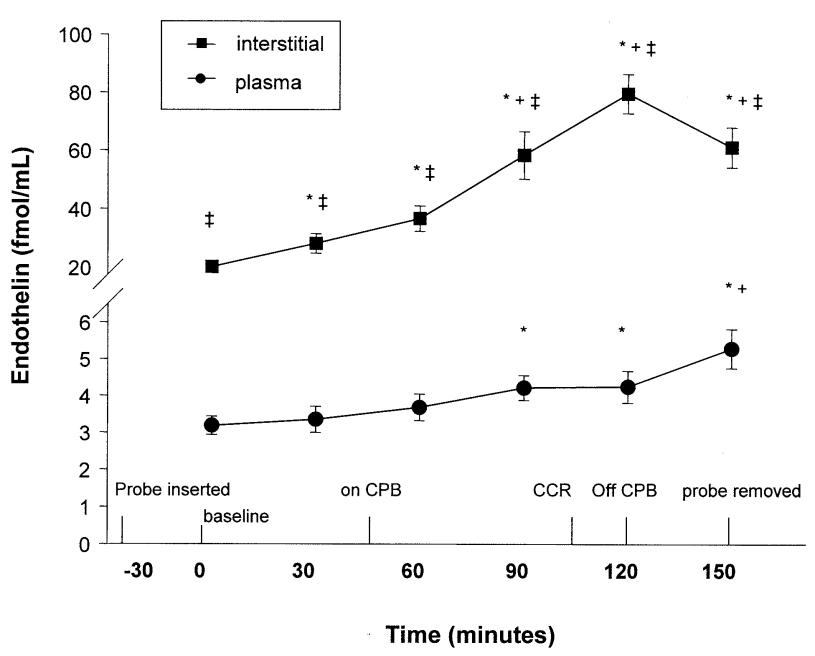

Figure 2. Systemic ET levels increased from baseline during CPB, at separation from CPB, and $\mathbf{3 0}$ minutes after CPB. Systemic ET levels were also higher 30 minutes after CPB as compared with pre-CPB values. Myocardial interstitial ET levels increased from baseline at all time points and also increased from pre-CPB values. Myocardial interstitial ET levels were higher than systemic ET at all time points. ${ }^{*} \boldsymbol{P}<.05$ vs baseline; ${ }^{+} \boldsymbol{P}<.05$ vs pre-CPB; $¥ P<.05$ vs systemic ET. $C P B$, Cardiopulmonary bypass; CCR, crossclamp release.

added. Bound and free labels were magnetically separated. Two sets of standards were constructed to support the range of ET within the 2 sample sets: 0.003 to $1.0 \mathrm{fmol} / \mathrm{mL}$ for the interstitial samples and 2.0 to $32.0 \mathrm{fmol} / \mathrm{mL}$ for the plasma samples. Although past studies have reported ET levels in picograms per milliliter, ${ }^{8,9}$ the present study as well as more recent reports have used a high-sensitivity assay that allows for ET measurements to be reported within the fentomolar range. ${ }^{6,11}$ A standard curve used for the plasma and microdialysis samples, which demonstrates the high sensitivity and operating range of this assay system, is shown in Figure 1. The interassay variation was $7 \%$ and $2 \%$ for the plasma and microdialysis ET measurements, respectively. The plasma ET concentrations were corrected for potential hemodilution artifact by using changes in hematocrit.

\section{Microdialysis Calibration}

The first set of calibration experiments determined the relative recovery of ET in the microdialysis system using a ${ }^{125}$ I-ET tracer as described previously. ${ }^{11}$ The relative recovery of ET at a flow rate of $2.5 \mu \mathrm{L} / \mathrm{min}$ was calculated to be $15 \% \pm 1 \%$, and this value was used as the correction factor for recovery of myocardial interstitial samples. A second set of validation experiments were performed in vivo in an anesthetized pig preparation described previously. ${ }^{11,14}$ All animals were treated and cared for in accordance with the National Institutes of Health "Guide for the Care and Use of Laboratory Animals" (National Research Council, Washington, DC, 1996). In brief, adult pigs ( $\mathrm{n}=3,25 \mathrm{~kg}$, Hambone Farms, Orangeburg, SC) were anesthetized with isoflurane $(3 \%)$, microdialysis probes placed, and ET microdialysis 
TABLE 2. Hemodynamic parameters before, during and after cardiopulmonary bypass (CPB)

\begin{tabular}{|c|c|c|c|c|c|c|}
\hline & \multirow[b]{3}{*}{ Baseline } & \multicolumn{5}{|c|}{ Time (min) } \\
\hline & & \multirow{2}{*}{$\begin{array}{c}30 \\
\text { (pre-CРB) }\end{array}$} & 60 & 90 & \multirow{2}{*}{$\begin{array}{c}120 \\
\text { (off CPB) }\end{array}$} & \multirow{2}{*}{$\begin{array}{l}150 \text { (probe } \\
\text { removed) }\end{array}$} \\
\hline & & & \multicolumn{2}{|c|}{ CPB } & & \\
\hline Heart rate (beats/min) & $72 \pm 3$ & $71 \pm 3$ & - & - & $79 \pm 3$ & $78 \pm 2$ \\
\hline Cardiac output (L/min) & $4.38 \pm 0.21$ & $4.40 \pm 0.23$ & - & - & $4.65 \pm 0.21$ & $5.10 \pm 0.15^{*} \dagger$ \\
\hline \multicolumn{7}{|l|}{ Pressures } \\
\hline Mean arterial $(\mathrm{mm} \mathrm{Hg})$ & $78 \pm 3$ & $76 \pm 2$ & $69 \pm 3^{*}$ & $72 \pm 2$ & $75 \pm 4$ & $76 \pm 3$ \\
\hline Mean pulmonary artery $(\mathrm{mm} \mathrm{Hg})$ & $14 \pm 1$ & $16 \pm 1$ & - & - & $13 \pm 1$ & $17 \pm 1^{*}$ \\
\hline Pulmonary capillary wedge $(\mathrm{mm} \mathrm{Hg})$ & $10 \pm 1$ & $10 \pm 1$ & - & - & $8 \pm 1$ & $9 \pm 1$ \\
\hline
\end{tabular}

Values presented as mean \pm SEM.

$* P<.05$ versus baseline.

$\dagger P<.05$ versus pre-CPB (30-minute time point).

TABLE 3. Basal plasma and myocardial interstitial endothelin levels $(\mathrm{fmol} / \mathrm{mL})$ : effects of gender, beta blockade, or $\mathrm{Ca}^{2+}$ channel blockers

\begin{tabular}{|c|c|c|c|c|}
\hline & Plasma & $P$ value & Interstitial & $P$ value \\
\hline \multicolumn{5}{|l|}{ Sex } \\
\hline Male $(n=15)$ & $3.41 \pm 0.29$ & .1323 & $20.00 \pm 2.69$ & .9324 \\
\hline Female $(n=5)$ & $2.54 \pm 0.37$ & & $20.42 \pm 2.27$ & \\
\hline \multicolumn{5}{|l|}{ Beta blockade ( $\beta$-blocker) } \\
\hline Receiving $\beta$-blocker ( $\mathrm{n}=11$ ) & $2.77 \pm 0.26$ & .0580 & $21.22 \pm 3.58$ & .5658 \\
\hline No $\beta$-blocker $(\mathrm{n}=9)$ & $3.70 \pm 0.40$ & & $18.74 \pm 1.62$ & \\
\hline \multicolumn{5}{|l|}{$\mathrm{Ca}^{2+}$ channel blockade (CCB) } \\
\hline Receiving CCB $(\mathrm{n}=7)$ & $2.87 \pm 0.36$ & .3663 & $21.23 \pm 2.26$ & .7017 \\
\hline No CCB $(n=13)$ & $3.36 \pm 0.33$ & & $19.50 \pm 2.99$ & \\
\hline
\end{tabular}

Values presented as mean \pm SEM.

measurements performed for up to 6 hours. ET values at 1- and 6-hour time points were $24 \pm 7$ and $25 \pm 8 \mathrm{fmoL} / \mathrm{mL}$, respectively $(P=.82)$. Thus, this microdialysis technique yielded reproducible interstitial ET values over time. To confirm that probe placement did not impede diffusion as well as reached a steady state within the interstitial compartment, a ${ }^{125}$ I-ET solution $(20 \mathrm{fmol} / \mathrm{mL}, 2.5$ $\mathrm{uL} / \mathrm{min}$, Amersham) was infused and dialysate radioactivity determined (Figure 1). At the end of the ${ }^{125}$ I-ET infusion period, the dialysate was immediately changed (using a servo-control system, CMA) to buffer and collection continued. ${ }^{125}$ I-ET reached steadystate levels by approximately 30 minutes. These results indicated a balance between the rate of ${ }^{125}$ I-ET infusion and the return of radiolabeled ET in the dialysate. With termination of the ${ }^{125} \mathrm{I}$-ET infusion, the dialysate concentration of radiolabeled ET fell in a time-dependent manner. After these experiments, the tissue was harvested and sections taken at 2-mm intervals from the probe tip. All the radioactive ET-1 remained compartmentalized within a $4-\mathrm{mm}$ radius around the probe, as no ${ }^{125}$ I-ET was detected in samples taken from greater distances. Thus, the radiolabeled ET remained within the interstitial space surrounding the microdialysis probe and could be modeled as a closed compartment system.

\section{Data Analysis}

Plasma and interstitial ET levels at each time point were evaluated with a 2-way analysis of variance (ANOVA). If the ANOVA revealed significant differences, individual group means were compared by pairwise adjusted Bonferroni probabilities. All statistical procedures were performed with the BMDP statistical software package (BMDP Statistical Software Inc, Los Angeles, Calif). Patient characteristics and perioperative data are presented as mean \pm SD. For categorical data such as graft number and incidence of pharmacologic support, a chi-square analysis was performed. All analytical parameters are presented as mean \pm SEM.

\section{Results}

Global hemodynamic parameters during the course of the sampling period are shown in Table 2. At 30 minutes after $\mathrm{CPB}$, cardiac output was higher and mean arterial pressure lower relative to baseline. Baseline myocardial interstitial ET levels were approximately 6-fold higher than systemic levels (Figure 2). There was a trend for patients receiving a beta-receptor antagonist to have lower plasma ET levels (Table 3). Before CPB, myocardial interstitial ET levels were higher than systemic plasma levels. Both the myocardial interstitial and plasma levels increased during CPB, and systemic ET levels increased from baseline during CPB and increased further at separation from $\mathrm{CPB}$ and 30 minutes 


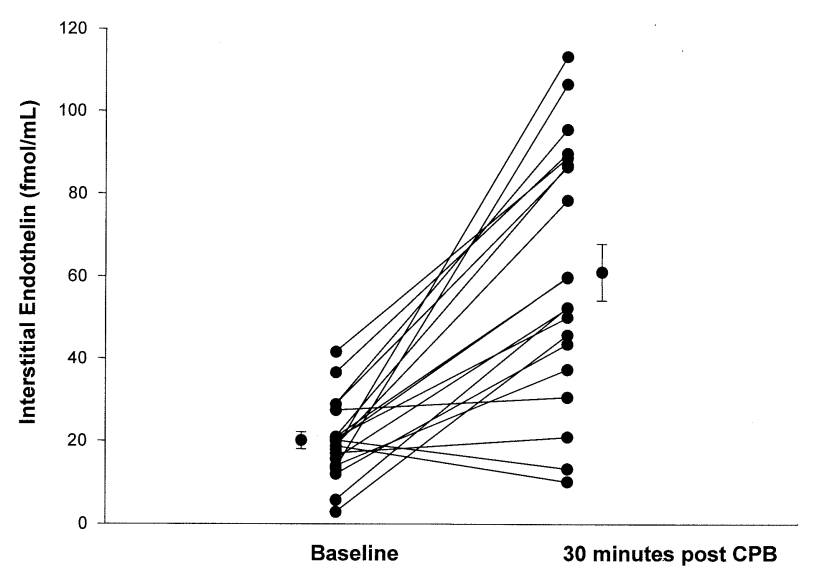

Figure 3. The individual response plots with respect to myocardial interstitial ET at baseline and 30 minutes after CPB was examined. Although the majority of patients demonstrated an increase from baseline, approximately 4 patients decreased or had no change from baseline.

after separation from CPB. Myocardial interstitial ET levels were higher than baseline values at all time points and increased further on separation from CPB (Figure 2). Although myocardial interstitial ET increased from baseline for the majority of patients, 4 patients demonstrated a decrease or no change at 30 minutes after CPB (Figure 3). Before surgery all 4 of these patients were receiving a beta-adrenergic receptor antagonist and 3 of these 4 patients were concomitantly receiving $95 \%$ of the patients at 6 hours postoperatively with $40 \%$ of the patients remaining on this vasodilator at 24 hours postoperatively. At 6 hours postoperatively, $60 \%$ of the patients were on intravenous epinephrine and all patients were removed from this vasoactive agent by 24 hours postoperatively. The intraoperative interstitial ET levels were not associated with the presence or absence of postoperative nitroglycerin or epinephrine administration. Duration of stay in intensive care unit was also not associated with intraoperative interstitial ET levels. However, an apparent relationship between postoperative length of stay (LOS) was observed with baseline myocardial interstitial ET levels. Specifically, in patients with a basal myocardial interstitial ET level of less than $15 \mathrm{fmol} / \mathrm{mL}$, LOS was $6.0 \pm 0.5$ days whereas in patients with interstitial ET levels of greater than $15 \mathrm{fmol} / \mathrm{mL}$, LOS was $10.1 \pm 1.3$ days $(P<.05)$.

\section{Discussion}

Postoperative LV pump dysfunction can occur after cardioplegia and CPB. ${ }^{4,6-10}$ The causes of this LV dysfunction are likely to be multifactorial and include neurohormonal system activation, changes in vascular resistance properties, and abnormalities in myocardial contractility. ${ }^{6,10,15-17}$ In the context of cardiac surgery, increased systemic plasma ET levels have been documented, which may affect systemic and pulmonary vascular resistance, the caliber/patency of the coronary conduits, and myocardial contractility. ${ }^{1,5,6,14,15,18-22}$ The present study used a precalibrated myocardial microdialysis system to measure the dynamics of ET within the interstitial compartment during and after myocardial arrest and CPB. The unique and important findings of the present study were 2-fold. First, ET levels were over 6-fold higher within the myocardial interstitium compared with simultaneous plasma measurements, indicating significant compartmentalization of this bioactive peptide within the human myocardium. Second, distinct and temporally disparate changes in myocardial interstitial ET occurred during and after $\mathrm{CPB}$ when compared with systemic plasma levels.

This is the first study that has placed a microdialysis probe in the human myocardium to measure changes in ET during and after cardioplegia and CPB. Past studies have employed similar techniques to interrogate the myocardial interstitium for the elaboration of relevant proteins in animal models. ${ }^{11-13}$ Dell'Italia and colleagues, ${ }^{12}$ using myocardial microdialysis, demonstrated that interstitial angiotensin II levels were 100-fold greater than that of plasma, indicating compartmentalization of this bioactive peptide. Using a pig model of heart failure, this laboratory has demonstrated previously that myocardial interstitial levels are significantly different than plasma levels and likely reflect alterations in synthesis and/or uptake by myocardial cells. ${ }^{11}$ These past studies also demonstrated that neurohormonal measurements performed in myocardial tissue homogenates will not reflect the dynamic nature of these signaling molecules. The present study builds on these past findings by interrogating the human myocardium for interstitial ET levels during and after cardioplegia and CPB. Specifically, myocardial interstitial ET levels increased early during CPB, whereas systemic ET levels remained unchanged from baseline. At separation from CPB, another surge in interstitial ET occurred, which was greater in magnitude than systemic levels. The results of the present study indicate that there is a clear compartmentalization of ET within the human myocardial interstitial space.

The present study demonstrated through the use of microdialysis that significant and prolonged exposure of the myocardial cells to ET occurs during and after cardioplegia and reperfusion. Past studies have shown that persistent ET receptor activation after cardioplegia can independently contribute to myocyte contractile dysfunction, which in turn could lead to an exacerbation of LV contractile dysfunction in the early setting after cardiac surgery. ${ }^{14}$ Although the present study was underpowered to properly address this issue, a past study with larger sample sizes documented increased inotropic requirements after CPB in those patients with higher intraoperative plasma ET levels. ${ }^{7}$ In a past study 
by Matheis and colleagues, ${ }^{9}$ systemic and coronary sinus levels of ET increased in a directional manner in patients after CPB, suggesting that ET "spillover" from the myocardial compartment had not occurred. Thus, whether and to what degree these systemic plasma levels reflect changes within the myocardial compartment remained unknown. The present study demonstrated a robust increase in ET levels within the myocardial interstitium after crossclamp release, indicating that a significant accumulation of ET occurred within the myocardial microenvironment, which would not necessarily be detected through the measurement of aortic and coronary sinus ET levels.

We demonstrated previously that the synthesis of ET occurs within the myocardial compartment and can be contained within cardiac myocytes. ${ }^{11}$ Moreover, this past study demonstrated robust levels of the ET converting enzyme. Local changes in $\mathrm{pH}$ and myocardial metabolism occur immediately after CPB and can directly influence the synthesis and release of several biologically active molecules such as ET. ${ }^{23}$ Hypothermia can alter the binding kinetics of the ET receptor, ${ }^{24}$ and therefore changes in myocardial temperature may have caused unstable ET binding kinetics. Based upon the findings of the present study, future studies should utilize microdialysis to determine the relationship between the release of endogenous ET, ET synthesis, and ET receptor activation in the context of CPB.

In a small subset of patients, interstitial ET levels were not increased with CPB. In these particular patients, 3 were treated with a 3-hydroxy-3-methylglutaryl coenzyme A reductase inhibitor (statins) and all of these patients received a beta-adrenergic receptor antagonist. Beyond reducing serum cholesterol levels, statins have been implicated to modify the release of bioactive peptides, reduce the magnitude of inflammatory response, and improve endothelial function. ${ }^{25,26}$ The synthesis and release of ET is under the regulation of several neurohormonal/inflammatory pathways as well as through local mechanical signals. ${ }^{1-4}$ Thus, the release of ET into the myocardial interstitial compartment during and after CPB was likely due to a summation of several upstream signaling events. Nevertheless, it can be hypothesized from the observational data regarding preoperative statin and beta-blocker therapy, specific pharmacologic pretreatment may modify the ET response during cardiac surgery.

ET has been demonstrated to contribute to vasoconstriction within the systemic and pulmonary circulatory systems. ${ }^{5-}$ 10,14,22 Systemic ET levels have been documented to increase during and after CPB. ${ }^{6-10}$ Specifically, Dorman and colleagues demonstrated a robust increase in plasma ET after CPB. ${ }^{7}$ As past studies have demonstrated a cause-effect relationship between ET receptor activation and blood pressure, ${ }^{5,14,18,22,23}$ then increased circulating levels of ET observed in the present study likely influence both systemic and pulmonary vascular resistance properties. Increased plasma ET levels in the postoperative period have been associated with longer ventilatory support and prolonged intensive care unit times and hospital stay. ${ }^{6,7}$ The present study demonstrated that higher baseline myocardial interstitial ET levels were associated with a longer postoperative hospital stay. However, this study was underpowered with respect to performing any predictive analysis on postoperative outcomes variables. Finally, a direct cause-andeffect relationship between elevated myocardial interstitial ET levels and adverse outcomes (ie, coronary vasospasm, depressed myocardial performance) could not be directly established in this limited study. Nevertheless, this unique intraoperative study clearly demonstrated that dynamic ET signaling changes occur within the myocardial interstitium of patients undergoing cardiac surgery. Future studies that directly relate the dynamic changes in myocardial interstitial ET levels to myocardial performance and clinical outcomes, as well as deploying pharmacological strategies that interrupt ET signaling in the perioperative cardiac surgical setting, are warranted.

\section{References}

1. Luscher T, Barton M. Endothelins and endothelin receptor antagonists. Therapeutic considerations for a novel class of cardiovascular drugs. Circulation. 2000;102:2434-40.

2. Miyauchi T, Masaki T. Pathophysiology of endothelin in the cardiovascular system. Annu Rev Physiol. 1999;61:391-415.

3. Giannessi D, Delry S, Vitale R. The role of endothelins and their receptors in heart failure. Pharmacol Res. 2001;43:111-26.

4. Spinale F. The bioactive peptide endothelin causes multiple biologic responses relevant to myocardial and vascular performance after cardiac surgery. J Thorac Cardiovasc Surg. 2002;123:1031-4.

5. Rubin LJ. Primary pulmonary hypertension. N Engl J Med. 1997;336: 111-7.

6. Bond BR, Dorman BH, Clair MJ, et al. Endothelin-1 during and after cardiopulmonary bypass: association to graft sensitivity and postoperative recovery. J Thorac Cardiovasc Surg. 2001;122:358-64.

7. Dorman BH, Bond BR, Clair MJ, et al. Temporal synthesis and release of endothelin within the systemic and myocardial circulation during and after cardiopulmonary bypass: relation to postoperative recovery. J Cardiothorac Vasc Anesth. 2000;14:540-5.

8. Lockowandt U, Bjessmo S, Franco-Cereceda A. Plasma levels and vascular effects of endothelin and big endothelin in patients with stable and unstable angina pectoris undergoing coronary bypass grafting. Eur J Cardiothorac Surg. 2002;21:218-23.

9. Matheis G, Haak T, Beyersdorf F, et al. Circulating endothelin in patients undergoing coronary artery bypass grafting. Eur J Cardiothorac Surg. 1995;9:269-74.

10. Verma S, Maitland A, Weisel R, et al. Increased endothelin-1 production in diabetic patients after cardioplegic arrest and reperfusion impairs coronary vascular reactivity: reversal by means of endothelin antagonism. J Thorac Cardiovasc Surg. 2002;123:1114-9.

11. Ergul A, Walker C, Goldberg A, et al. ET-1 in the myocardial interstitium: relation to myocytes ECE activity and expression. Am J Physiol. 2000;278:H2050-6.

12. Dell'Italia L, Meng QC, Balcells E, et al. Compartmentalization of angiotensin II generation in the dog heart. J Clin Invest. 1997;100: 253-8.

13. Wei CC, Meng QC, Palmer R, et al. Angiotensin peptides modulate bradykinin levels in the interstitium of the dog heart in vivo. J Pharm Exp Ther. 2002;300:324-9.

14. Krum H, Viskoper RJ, Lacourciere Y, et al. The effect of an endothelin receptor antagonist, bosentan, on blood pressure in patients with essential hypertension. N Engl J Med. 1998;338:784-90. 
15. Dorman BH, New RB, Bond BR, et al. Myocyte endothelin exposure during cardioplegic arrest exacerbates contractile dysfunction after reperfusion. Anesth Analg. 2000;90:1080-5.

16. Zamparelli R, De Paulis S, Martinelli L, et al. Pulsatile normothermic cardiopulmonary bypass and plasma catecholamine levels. Perfusion. 2000;15:217-23.

17. Minami K, Korner M, Vyska K, et al. Effects of pulsatile perfusion on plasma catecholamine levels and hemodynamics during and after cardiac operations with cardiopulmonary bypass. J Thorac Cardiovasc Surg. 1990;99:82-91.

18. Luscher TF, Enseleit F, Pacher R, et al. Hemodynamic and neurohormonal effects of selective endothelin a $\left(\mathrm{ET}_{\mathrm{A}}\right)$ receptor blockade in chronic heart failure. Circulation. 2002;106:2666-72.

19. Goldberg AT, Bond BR, Mukherjee R, et al. The endothelin receptor pathway in human LV myocytes and their relation to contractility. Ann Thorac Surg. 2000;59:711-15.

20. Thomas PB, Liu EC, Webb ML, et al. Exogenous effects and endogenous production of endothelin in cardiac myocytes: potential significances in heart failure. Am J Physiol. 1996;40:H2629-37.
21. Petrossian E, Parry AJ, Reddy VM, et al. Endothelin receptor blockade prevents the rise in pulmonary vascular resistance after cardiopulmonary bypass in lambs with increased pulmonary blood flow. $J$ Thorac Cardiovasc Surg. 1999;117:314-23.

22. Joffs C, Walker CA, Hendrick JW, et al. Endothelin receptor subtype a blockade selectively reduces pulmonary pressure after cardiopulmonary bypass. J Thorac Cardiovasc Surg. 2001;122:365-70.

23. Hiramatsu T, Forbess JM, Miura T, Roth SJ, Cioffi MA, Mayer JE Jr. Effects of endothelin-1 and L-arginine after cold ischemia in lamb hearts. Ann Thorac Surg. 1996;61:36-40.

24. Liu J, Chen R, Casley DJ, Nayler WG. Ischemia and reperfusion increase 125I-labeled endothelin-1 binding in rat cardiac membranes. Am J Physiol. 1990;258:H829-835.

25. Jones SP, Trocha SD, Lefer DJ. Pretreatment with simvastatin attenuates myocardial dysfunction after ischemia and chronic reperfusion. Arterioscler Thromb Vasc Biol. 2001;21:2059-64.

26. Chan AW, Bhatt DL, Chew DP, et al. Early and sustained survival benefit associated with statin therapy at the time of percutaneous coronary intervention. Circulation. 2002;105:691-6.

Access to The Journal of Thoracic and Cardiovascular Surgery Online is reserved for print subscribers!

Full-text access to The Journal of Thoracic and Cardiovascular Surgery Online is available for all print subscribers. To activate your individual online subscription, please visit The Journal of Thoracic and Cardiovascular Surgery Online, point your browser to http://www.mosby.com/itcvs, follow the prompts to activate your online access, and follow the instructions. To activate your account, you will need your subscriber account number, which you can find on your mailing label (note: the number of digits in your subscriber account number varies from 6 to 10). See the example below in which the subscriber account number has been circled:

\section{Sample mailing label}

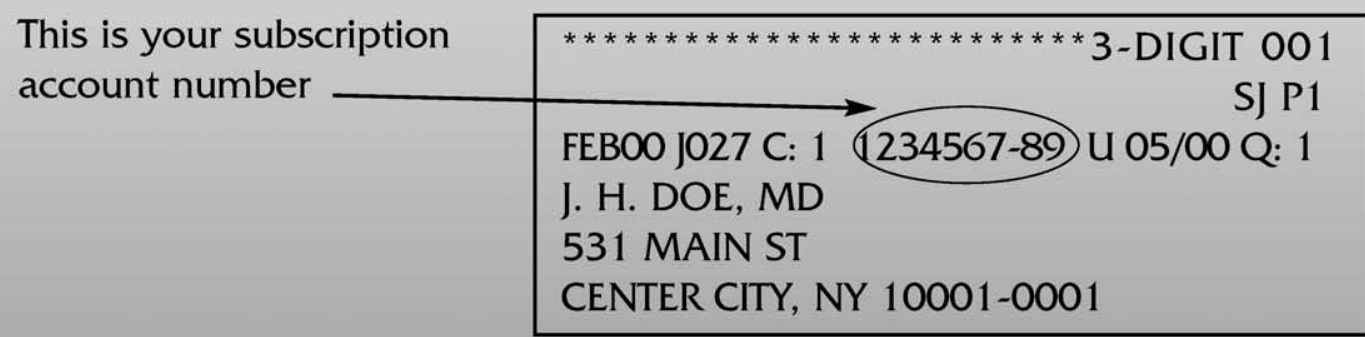

Personal subscriptions to The Journal of Thoracic and Cardiovascular Surgery Online are for individual use only and may not be transferred. Use of The Journal of Thoracic and Cardiovascular Surgery Online is subject to agreement to the terms and conditions as indicated online. 